\title{
Venoarterial Extracorporeal Membrane Oxygenation for Acute Massive Pulmonary Embolism: a Meta-Analysis and Call to Action
}

\author{
Elona Rrapo Kaso ${ }^{1}$ • Jonathan A. Pan ${ }^{1} \cdot$ Michael Salerno ${ }^{1,2,3} \cdot$ Alexandra Kadl $^{4}$ - Chad Aldridge ${ }^{5}$ Ziv J. Haskal ${ }^{2}$. \\ Jamie L. W. Kennedy ${ }^{6} \cdot$ Sula Mazimba $^{1} \cdot$ Andrew D. Mihalek $^{4} \cdot$ Nicholas R. Teman $^{7} \cdot$ Jay Giri $^{8} \cdot$ Herbert D. Aronow $^{9}$. \\ Aditya M. Sharma ${ }^{1}$ (B)
}

Received: 23 February 2021 / Accepted: 9 July 2021 / Published online: 19 July 2021

(C) The Author(s), under exclusive licence to Springer Science+Business Media, LLC, part of Springer Nature 2021

\begin{abstract}
Venoarterial extracorporeal membrane oxygenation (ECMO) has been used to treat acute massive pulmonary embolism (PE) patients. However, the incremental benefit of ECMO to standard therapy remains unclear. Our meta-analysis objective is to compare in-hospital mortality in patients treated for acute massive PE with and without ECMO. The National Library of Medicine MEDLINE (USA), Web of Science, and PubMed databases from inception through October 2020 were searched. Screening identified 1002 published articles. Eleven eligible studies were identified, and 791 patients with acute massive PE were included, of whom 270 received ECMO and 521 did not. In-hospital mortality was not significantly different between patients treated with vs. without ECMO $(\mathrm{OR}=1.24$ [95\% CI, 0.63-2.44], $p=0.54)$. However, these findings were limited by significant study heterogeneity. Additional research will be needed to clarify the role of ECMO in massive PE treatment.
\end{abstract}

Keywords Venoarterial extracorporeal membrane oxygenation $\cdot$ Massive or high-risk pulmonary embolism

\section{Introduction}

The yearly incidence of pulmonary embolism (PE) in the USA is 115 per 100,000, with approximately 100,000 annual deaths (1-3). This incidence may further increase in the current pandemic as PE is reported in 2.6-8.9\% of hospitalized patients

Elona Rrapo Kaso and Jonathan A. Pan are co-first authors.

Associate Editor Navin Kumar Kapur oversaw the review of this article

Aditya M. Sharma

asharma@virginia.edu

1 Department of Medicine, Cardiovascular Division, University of Virginia, 1215 Lee Street, Charlottesville, VA, USA

2 Department of Radiology and Medical Imaging, University of Virginia, Charlottesville, VA, USA

3 Department of Biomedical Engineering, University of Virginia, Charlottesville, VA, USA

4 Department of Medicine, Division of Pulmonary and Critical Care, University of Virginia, Charlottesville, VA, USA with coronavirus disease-2019 (COVID-19) and up to onethird of those requiring intensive care unit admission (4). About 5\% of all acute PEs are massive (5). Systemic thrombolysis (ST) reduces the risk of PE-related mortality and the composite all-cause death or treatment escalation by $85 \%$ and $80 \%$, respectively (6). However, many patients presenting

5 Department of Therapy Services, University of Virginia, Charlottesville, VA, USA

6 Division of Cardiology, Inova Heart and Vascular Institute, Falls Church, VA, USA

7 Department of Surgery, Division of Thoracic and Cardiovascular Surgery, University of Virginia, Charlottesville, VA, USA

8 Division of Cardiology, Warren Alpert Medical School of Brown University, Providence, RI, USA

9 Department of Internal Medicine, University of Pennsylvania, Philadelphia, PA, USA 
with acute massive PE are not candidates for systemic thrombolysis. Stein PD et al. used the Nationwide Inpatient Sample database and reported a significant reduction in mortality in unstable PE with the use of thrombolytic therapy (15\% vs. $47 \% ; p<.0001)$. The study also reported that only $30 \%$ $(21,390$ of 72,230$)$ received thrombolytic therapy (7). Similarly, the RIETE registry reported that only 20\% (238/ 1207) of patients with acute PE and hemodynamic instability received thrombolytic therapy. For patients in whom systemic thrombolytic therapy is contraindicated or has failed, venoarterial extracorporeal membrane oxygenation (ECMO) can serve as a bridge to catheter-directed therapies (CDT) or surgical pulmonary embolectomy (SPE) (8). ECMO can hemodynamically stabilize patients who manifest with shock or cardiac arrest by providing full mechanical circulatory support and oxygenating the circulating blood $(9,10)$. Nevertheless, the impact of ECMO on survival in these patients is not wellreported. Limited data from case series and case reports suggest that ECMO may improve morbidity and mortality in this setting (11). Our meta-analysis objective is to compare inhospital mortality in patients treated for acute massive PE with vs. without ECMO.

\section{Methods}

\section{Literature Search Strategy and Selection}

A meta-analysis was performed according to Metaanalysis of Observational Studies in Epidemiology guidelines (12), Preferred Reporting Items for Systematic Reviews and Meta-Analyses documents, and Methodological Standards for Meta-Analyses (13), and Qualitative Systematic Reviews of Cardiac Prevention and Treatment Studies (14). The National Library of Medicine MEDLINE (USA), Web of Science, and PubMed databases were systematically searched from inception through October 2020 using Medical Subject Headings and text words, supplemented by scanning bibliographies of the recovered articles. Keywords used included "Pulmonary embol*" AND "Extracorporeal" in all fields. Three authors (JAP, ERK, and AMS) reviewed and selected relevant articles based on the following eligibility criteria: (a) included adults greater than 18 years of age with massive/high-risk pulmonary embolism as defined by the American Heart Association (AHA) scientific statement (15), (b) enrolled patients were treated with and without venoarterial ECMO, and (c) reported inhospital mortality. Only English-language manuscripts appearing in peer-reviewed journals were included. Abstracts, case reports, conference presentations, editorials, and expert opinions were excluded.

\section{Data Extraction and Critical Appraisal}

Data from each study was individually extracted by three investigators (ERK, JAP, AMS). In the event of overlapping studies, a single study was chosen based on data availability, quality of methodology, and sample size. Any uncertainties were resolved by consultation with the senior reviewer (AMS). Abstracted covariates included study population, intensive care unit and hospital length of stay, ECMO duration, presence of cardiogenic shock or cardiac arrest prior to initiation of ECMO, ECMO duration, and additional therapies (ST, SPE, and CDT), $\mathrm{pH}$, and lactate level. ECMO was classified as primary or salvage therapy. Salvage therapy was defined as ECMO used for rescue therapy when other therapies were not successful and when patients were still considered at high risk for early mortality from PE. When ECMO was used before the initiation of other therapies, it was considered primary therapy. The risk of bias was assessed by using the ROBINS-I tool (Risk Of Bias In Non-randomized Studies - of Interventions) by the Cochrane Handbook of Systematic Reviews (16).

\section{Statistical Analysis}

Statistical analysis was performed according to the Cochrane Collaboration using Review Manager (RevMan) (computer program) Version 5.3. Copenhagen: The Nordic Cochrane Center, The Cochrane Collaboration, 2014. The primary outcome was in-hospital mortality compared between patients undergoing treatment with and without ECMO. Inverse variance odds ratio (OR) point estimates and associated $95 \%$ confidence intervals (CIs) were calculated using a random-effects model. Heterogeneity was assessed using the $I^{2}$ measure, which is an estimated percentage of total variation across studies due to heterogeneity rather than chance. $I^{2}$ measures greater than $50 \%$ were considered to reflect substantial heterogeneity. Sensitivity analyses (including the exclusion of 1 study at a time) were also conducted to explore heterogeneity. Publication bias was assessed using funnel plots (plotting of standard error of the logarithm of the OR against log of OR), Peter's test, and Egger's test $(17,18)$.

The pooling of covariates and meta-regression were performed using "metafor" and "meta" package in R version 3.6.1 (R Foundation for Statistical Computing, Vienna, Austria). Pooled covariates and 95\% CI were calculated based on either inverse variance method or sample size. Metaregression was used to compare the mortality odds ratio with study-level covariates including age, gender, year of publication, and rate of cardiac arrest. Other covariates were excluded due to insufficient reporting in most studies.

Dichotomous variables are presented as frequencies with percentages and continuous variables as mean \pm standard deviation or median with interquartile range, as appropriate. All $p$ values $\leq 0.05$ were considered statistically significant. 


\section{Results}

\section{Published Articles}

Study characteristics appear in Table 1. The search identified 1002 published articles from 1992 to 2020, eleven of which were included (all retrospective case series) (Fig. 1). Eight were single-center experiences, two were multi-center studies, and one publication was from a cardiovascular surgery database, including 538 hospitals. Four of the 11 studies were published in the USA, three in Asia, and four in Europe. There were 791 subjects with massive pulmonary embolism, 270 underwent venoarterial ECMO, and 521 did not. All studies included information regarding the use of advanced therapies such as SPE, CDT, and ST. Seven studies reported the incidence of cardiac arrest in patients presenting with massive PE.

\section{Patient Characteristics}

Patient characteristics for the ECMO treatment and nonECMO treatment groups are shown in Tables 2 and 3, respectively. The pooled mean age was 51 (95\% CI, 44-59) for the ECMO group and 61 (95\% CI, 55-68) for the non-ECMO group. The pooled proportion of men in each group was similar, $46 \%$ (95\% CI, 37-55\%) for the ECMO group and $46 \%$ (95\% CI, 35-58\%) for the non-ECMO group. The pooled percentage of patients that received ST was 30\% (95\% CI, $12-56 \%$ ) in the ECMO group and $46 \%$ (95\% CI, 32-62\%) in the non-ECMO group. The pooled percentage of patients that received an advanced therapy such as ST, CDT, or SPE was $67 \%(95 \% \mathrm{CI}, 49-81 \%)$ in the ECMO group and $73 \%$ (95\% CI, 55-85\%) in the non-ECMO group. The pooled incidence of cardiac arrest was 64\% (95\% CI, 44-80\%) and $49 \%$ (95\% CI, 22-77\%) in the ECMO and non-ECMO group respectively. The pooled duration of ECMO was 4.15 days (95\% CI, 0.7-7.6 days). The pooled proportion of patients who underwent ECMO as salvage therapy was $90 \%(95 \%$ CI, 35-99\%).

\section{In-hospital Mortality}

The pooled in-hospital mortality incidence was $46 \%$ (95\% CI, $31-61 \%$ ) and $40 \%$ (95\% CI, 25-58\%) for the ECMO and non-ECMO group, respectively. The forest plot in Fig. 2 shows that the odds ratio was 1.24 (95\% CI, 0.63-2.44), suggesting no significant difference in mortality rates $(p=0.54)$. There was high heterogeneity across the studies $(I=54 \%)$.

Table $1 \quad$ Study characteristics

\begin{tabular}{|c|c|c|c|c|c|c|c|c|c|c|}
\hline Studies & $\begin{array}{l}\text { Study } \\
\text { design }\end{array}$ & $\begin{array}{l}\text { Recruitment } \\
\text { period }\end{array}$ & Country & $\begin{array}{l}\text { ECMO } \\
(n)\end{array}$ & $\begin{array}{l}\text { Non- } \\
\text { ECMO } \\
(n)\end{array}$ & $\begin{array}{l}\text { ECMO } \\
\text { duration } \\
\text { (days) }\end{array}$ & $\begin{array}{l}\text { ICU } \\
\text { LOS } \\
\text { (days) }\end{array}$ & $\begin{array}{l}\text { Hospital } \\
\text { LOS (days) }\end{array}$ & $\begin{array}{l}\text { Salvage } \\
\text { therapy } \\
(\%)\end{array}$ & $\begin{array}{l}\text { Primary } \\
\text { therapy } \\
(\%)\end{array}$ \\
\hline $\begin{array}{l}\text { Caroll et al. } \\
\text { (2017) }\end{array}$ & $\begin{array}{l}\text { Single } \\
\text { center }\end{array}$ & 2015-2016 & USA & 2 & 9 & - & - & - & - & - \\
\hline $\begin{array}{l}\text { Kjaergaard } \\
\text { et al. (2019) }\end{array}$ & $\begin{array}{l}\text { Single } \\
\text { center }\end{array}$ & 2008-2014 & Denmark & 22 & 16 & $1.2 \pm 1.9$ & - & - & 100 & 0 \\
\hline $\begin{array}{l}\text { Maggio et al. } \\
\text { (2007) }\end{array}$ & $\begin{array}{l}\text { Single } \\
\text { center }\end{array}$ & $1992-2005$ & USA & 19 & 22 & $4.7 \pm 4.0$ & - & - & 100 & 0 \\
\hline $\begin{array}{l}\text { Mandigers } \\
\text { et al (2019) }\end{array}$ & Multicenter & 2014-2017 & Netherlands & 19 & 20 & $3[2-5]$ & $\begin{array}{l}19 \\
\quad[10-3- \\
5.5]\end{array}$ & - & 100 & \\
\hline $\begin{array}{l}\text { Meneveau } \\
\text { et al. (2018) }\end{array}$ & Multicenter & 2014-2015 & France & 52 & 128 & $2.5[1.0-7.0]$ & $4[2-16]$ & - & - & - \\
\hline $\begin{array}{l}\text { Minakawa } \\
\text { et al. (2018) }\end{array}$ & Database & 2008-2014 & Japan & 94 & 261 & - & - & - & - & - \\
\hline $\begin{array}{l}\text { Moon et al. } \\
\quad(2018)\end{array}$ & $\begin{array}{l}\text { Single } \\
\text { center }\end{array}$ & 2004-2017 & Korea & 14 & 9 & $8.0 \pm 8.1$ & - & $42 \pm 15$ & 100 & 0 \\
\hline $\begin{array}{l}\text { Pasrija, Shah } \\
\text { et al. (2018) }\end{array}$ & $\begin{array}{l}\text { Single } \\
\text { center }\end{array}$ & 2010-2017 & USA & 34 & 22 & 5.8 [4.3-6.7] & 10 [8-16] & 12 [10-20] & 3 & 97 \\
\hline $\begin{array}{c}\text { Slawek-Szmyt } \\
\text { et al (2020) }\end{array}$ & $\begin{array}{l}\text { Single } \\
\text { center }\end{array}$ & 2018-2019 & Poland & 2 & 12 & - & - & - & - & - \\
\hline $\begin{array}{r}\text { Wu et al. } \\
\text { (2013) }\end{array}$ & $\begin{array}{l}\text { Single } \\
\text { center }\end{array}$ & 2003-2012 & Taiwan & 7 & 17 & - & - & - & 100 & 0 \\
\hline $\begin{array}{l}\text { Xenos et al. } \\
\text { (2019) }\end{array}$ & $\begin{array}{l}\text { Single } \\
\text { center }\end{array}$ & 2015-2017 & USA & 5 & 5 & - & - & - & - & - \\
\hline
\end{tabular}

Continuous variables as mean \pm standard deviation or median [interquartile range]

$E C M O$ extracorporeal membrane oxygenation, ICU intensive care unit, LOS length of stay, $n$ number 


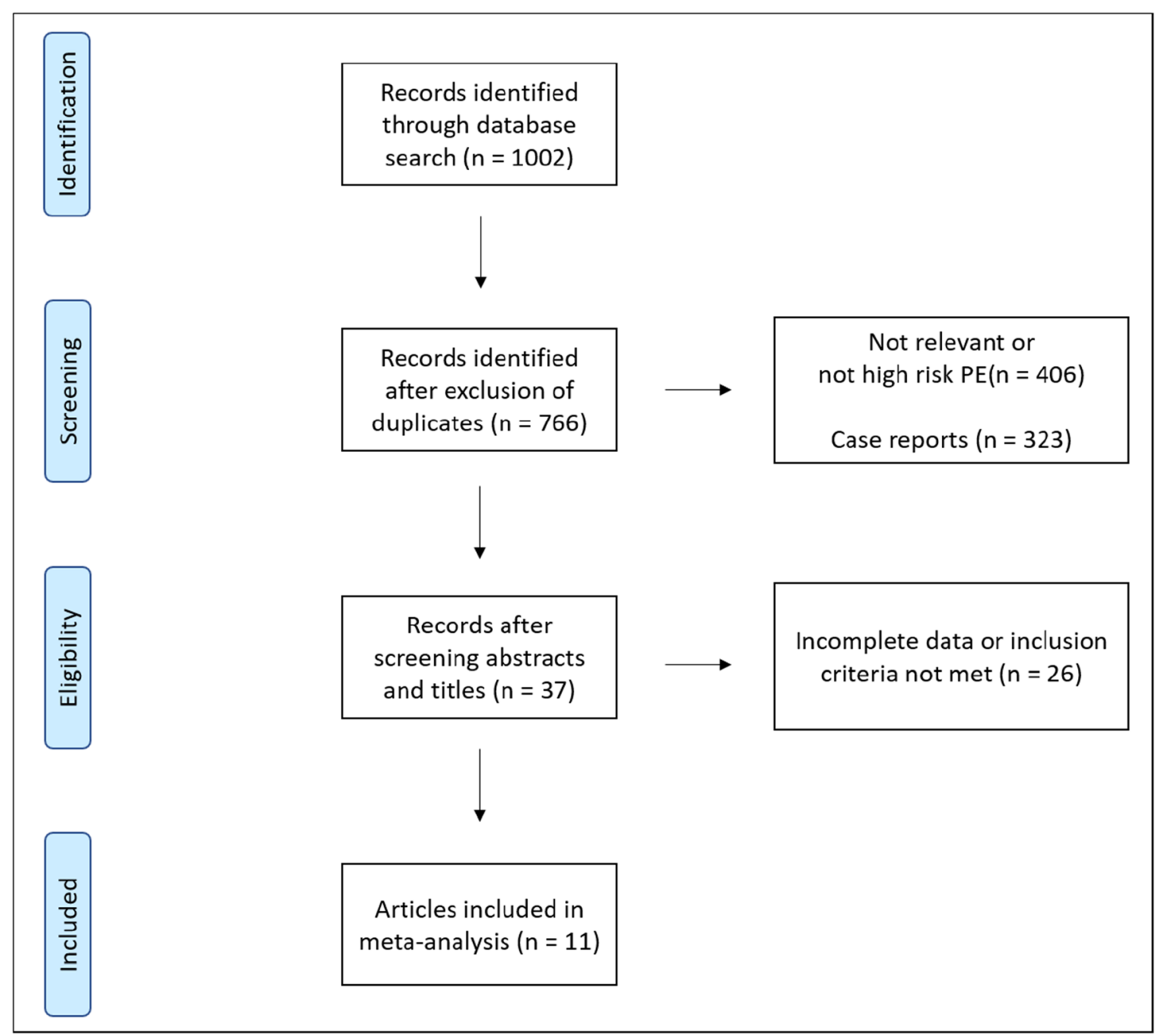

Fig. 1 Literature search strategy identified 1002 studies from 1992 to 2020. Screening abstracts and titles resulted in the exclusion of 236 duplicates and 729 studies that were not relevant for this meta-analysis.

Therefore, we performed a sensitivity analysis. There was an improvement of heterogeneity with the removal of the Mandigers L et al. (19) $(I=47 \%)$, Maggio P et al. (20) $(I=$ $46 \%)$, and Wu MY et al (21) $(I=48 \%)$ studies. However, mortality remained similar after the exclusion of each study individually. The meta-regression analysis demonstrated a significant association between the number of patients with cardiac arrest and in-hospital mortality $(p=0.0006)$. There was no significant association between publication year, age, gender, or use of ST and mortality ( $p=0.37,0.68,0.057$, and 0.94 , respectively).

\section{Quality and Bias Assessment}

Bias analysis was conducted for studies of patients treated with and without ECMO. No evidence of publication bias was observed in the funnel plot (Fig. 3). Peter's and Egger's tests also showed no evidence of publication bias. ROBINS-I
Of the 37 reviewed studies, 26 were determined to not be eligible for inclusion. The final meta-analysis included 11 studies in total

demonstrated an overall moderate risk of bias from the included studies (Table 4).

\section{Discussion}

The right ventricle (RV) is thin-walled compared to the left ventricle, with limited capacity to accommodate a significant increase in pulmonary vascular resistance (PVR). Pulmonary circulation usually is a low-pressure and low-resistance circuit. In the presence of an acute massive PE, typically associated with extensive thrombus burden in the pulmonary arteries, there is a sudden increase in PVR, leading to RV's inability to adequately contract, leading to RV failure $(22,23)$. Venoarterial ECMO bypasses the pulmonary circulation and can help acute massive pulmonary embolism by restoring adequate cardiac output and improving coronary artery and systemic perfusion (9). ECMO can be used as a supportive 


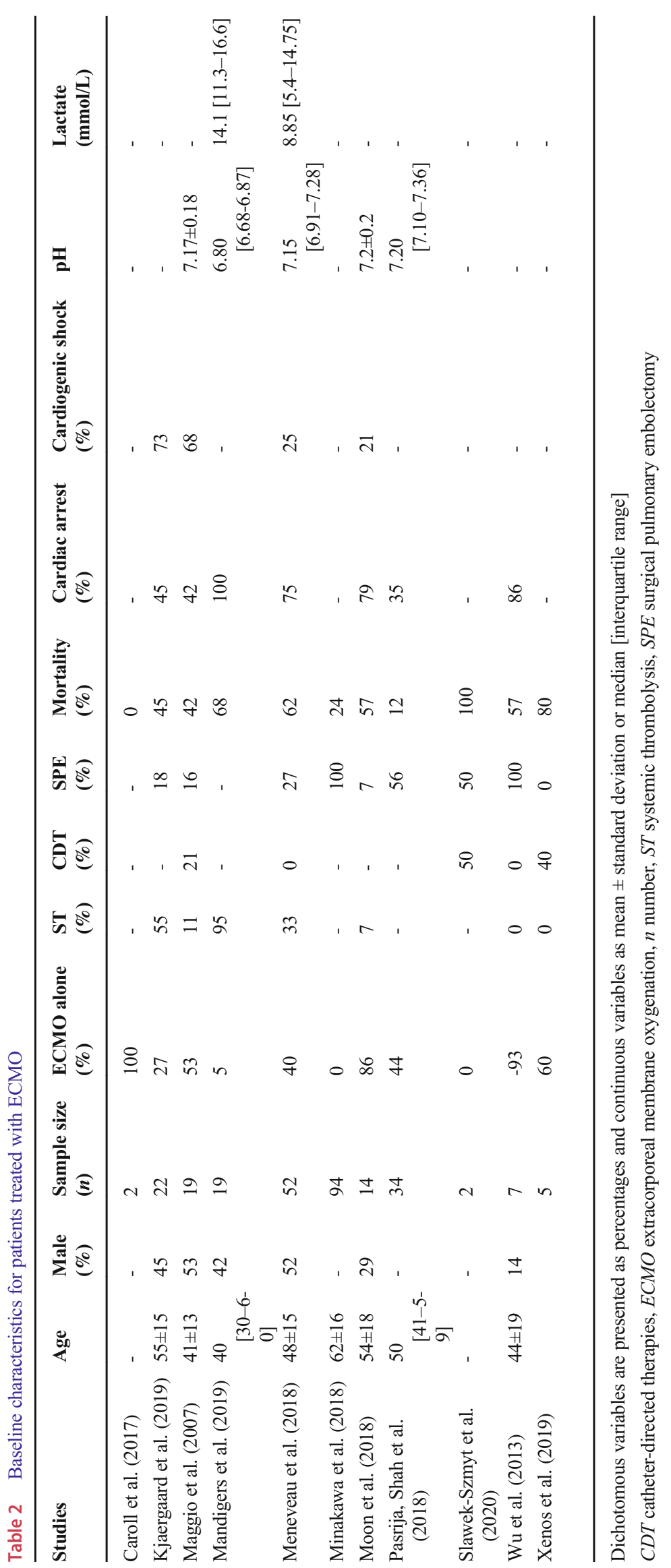




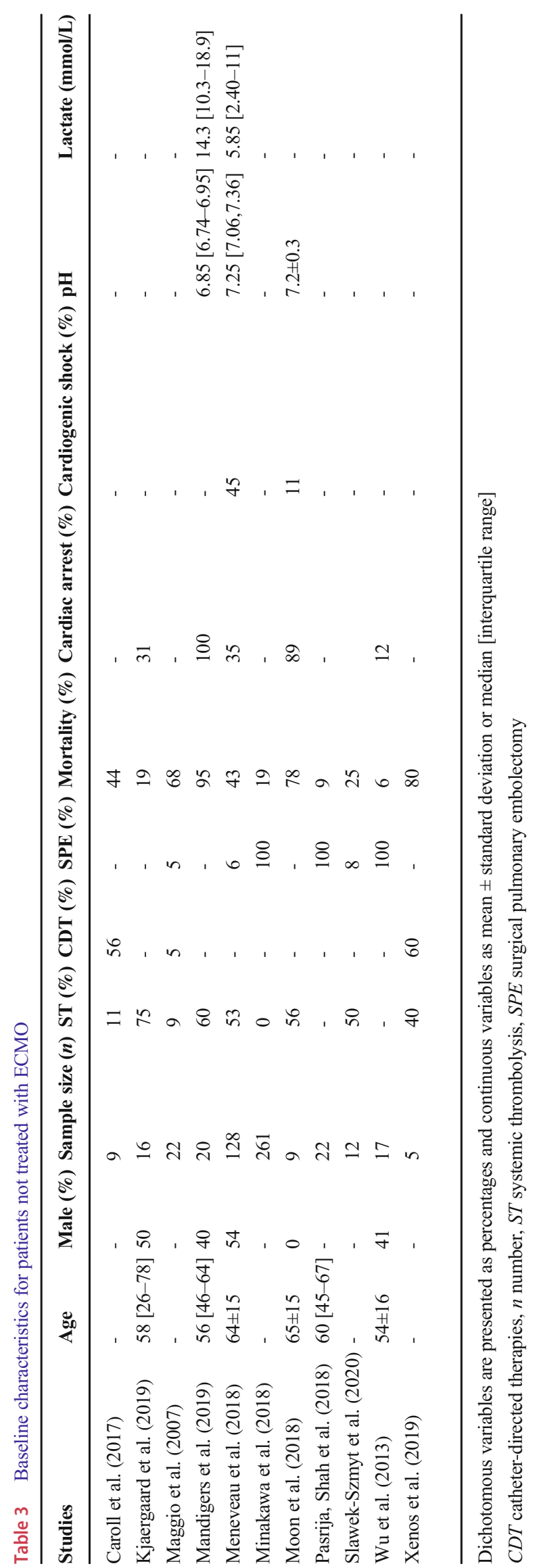


Fig. 2 Forests plots comparing ECMO and non-ECMO groups. Pooled in-hospital mortality demonstrated a non-significant odds ratio of $1.24(p=0.54)$.

There was significant heterogeneity of $I^{2}=54 \%$ among the studies. Odds ratios of individual studies are shown with blue squares with lines representing the $95 \%$ confidence interval. The black diamond demonstrates the pooled odds ratio and $95 \%$ confidence interval

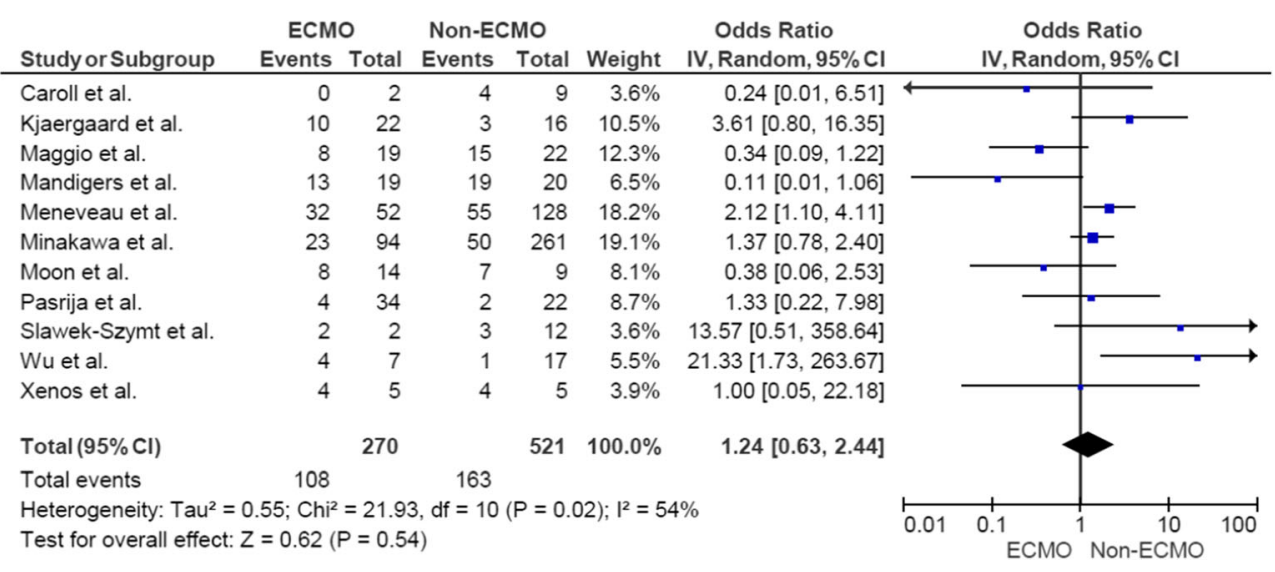

modality to maintain systemic circulation until other advanced therapies such as CDT, SE, or ST can be administered to treat massive PE.

The most recent 2019 AHA scientific statement suggests that patients with massive $\mathrm{PE}$ who require therapeutic escalation through SE, CDT, or ST may be supported by ECMO while these therapies are administered (15). There has been an increasing trend toward utilizing ECMO for massive PE as a bridge to other adjunctive therapies such as SE, CDT, or ST (24). The 2019 European Society of Cardiology (ESC) clinical guidelines have provided a class II b recommendation for ECMO when used in combination with SE or CDT in refractory circulatory collapse or cardiac arrest (25). However, its use in this setting is supported by case series and reports.

Our meta-analysis included 11 studies with 791 subjects; we compared in-hospital mortality in patients treated with and without ECMO. We found no significant difference in outcomes between the two groups. Our pooled in-hospital mortality incidence for patients placed on ECMO was $46 \%(95 \%$ CI, 0.31-0.61\%). A meta-analysis from Pozzi M et al. (26) reported an in-hospital survival that ranged from 38.4 to $95 \%$, though the results were limited by study heterogeneity $\left(I^{2}=\right.$ $73.7 \%$ ). They reported in-hospital survival with good neurological outcomes between 50 and 95\%; however, they did not

Table 4 ROBIN-I tool for non-randomized studies

\begin{tabular}{|c|c|c|c|c|c|c|c|c|}
\hline $\begin{array}{l}\text { First Author, } \\
\text { Year }\end{array}$ & $\begin{array}{l}\text { Bias due to } \\
\text { confounding }\end{array}$ & $\begin{array}{c}\text { Bias in } \\
\text { selection of } \\
\text { participants } \\
\text { into the study }\end{array}$ & $\begin{array}{c}\text { Bias in } \\
\text { classification } \\
\text { of } \\
\text { interventions }\end{array}$ & $\begin{array}{l}\text { Bias due to } \\
\text { deviations } \\
\text { from } \\
\text { intended } \\
\text { interventions }\end{array}$ & $\begin{array}{l}\text { Bias due to } \\
\text { missing } \\
\text { data }\end{array}$ & $\begin{array}{c}\text { Bias in } \\
\text { measurement } \\
\text { of outcomes }\end{array}$ & $\begin{array}{c}\text { Bias in } \\
\text { selection of } \\
\text { the reported } \\
\text { result }\end{array}$ & $\begin{array}{c}\text { Overall Risk } \\
\text { of Bias }\end{array}$ \\
\hline Carroll, 2017 & Inconclusive & Inconclusive & Inconclusive & Inconclusive & Inconclusive & Low & Low & Inconclusive \\
\hline Kjaegaard, 2019 & Critical & Inconclusive & Moderate & Serious & Inconclusive & Moderate & Moderate & Serious \\
\hline Maggio, 2006 & Critical & Inconclusive & Moderate & Moderate & Inconclusive & Inconclusive & Inconclusive & Inconclusive \\
\hline Mandigers, 2019 & Serious & Low & Low & Moderate & Inconclusive & Low & Low & Moderate \\
\hline Meneveau, 2018 & Critical & Low & Low & Serious & Inconclusive & Low & Low & Moderate \\
\hline Minakawa, 2019 & Critical & Inconclusive & Inconclusive & Inconclusive & Inconclusive & Low & Serious & Inconclusive \\
\hline Moon, 2018 & Serious & Moderate & Moderate & Serious & Inconclusive & Low & Low & Moderate \\
\hline Pasrija, 2018 & Serious & Serious & Serious & Low & Low & Low & Low & Moderate \\
\hline $\begin{array}{l}\text { Slawek-Szmyt, } \\
2020\end{array}$ & Critical & Inconclusive & Serious & Moderate & Inconclusive & Low & Low & Serious \\
\hline $\mathrm{Wu}, 2013$ & Critical & Inconclusive & Moderate & Serious & Inconclusive & Low & Moderate & Moderate \\
\hline
\end{tabular}


Fig. 3 Funnel plot for studies comparing ECMO vs non-ECMO groups. The treatment effect is plotted on the $\mathrm{x}$-axis (odds ratio) and precision (standard error of odds ratio) is plotted $y$-axis. There was symmetric heterogeneity, suggesting a publication bias is unlikely. Circles represent individual studies and blue line represents $95 \%$ confidence interval using fixed effects assumption

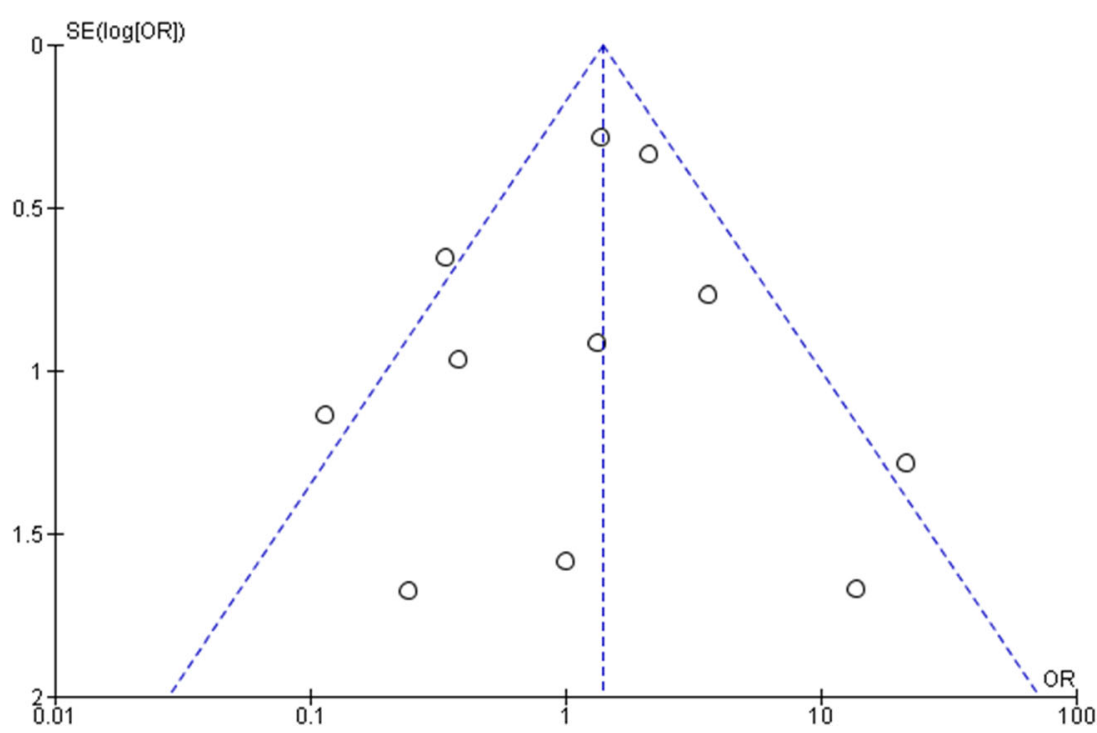

compare in-hospital mortality in patients treated with and without ECMO, which was the focus of our meta-analysis. Additionally, we provided a further pooled proportion of sex differences, use of advanced therapies, and incidence of cardiac arrest between the ECMO and the non-ECMO group. We also provided a pooled proportion of patients undergoing ECMO as salvage therapy being 90\% (95\% CI, 35-99\%), describing its utilization method. Elbadawi A et al. assessed the National Inpatient Sample database and identified 77,809 hospitalizations for massive PE from 2005 to 2013. Inhospital mortality for patients receiving ECMO was $61.6 \%$, with no change over the observational period $(p=68)$. In this study, ECMO use in massive PE was associated with lower mortality $(p<0.001)$. They performed multivariate regression analysis and reported a history of chronic lung disease or heart failure, obesity, advanced age, and female sex as independent predictors of mortality with ECMO use in massive PE.

In our meta-analysis, the ECMO group had a high pooled cardiac arrest rate of $64 \%(95 \% \mathrm{CI}, 44-80 \%)$ and that the majority of studies reported the use of ECMO as salvage therapy. Also, cardiac arrest was shown to be a significant covariate of in-hospital mortality. Due to a lack of patient-level data, we could not report in-hospital mortality only in patients with cardiac arrest treated with and without ECMO. Interestingly, studies with high cardiac arrest rates in both ECMO and nonECMO groups such as those of Mandingers L et al. (19) and Moon D et al. (27) had ORs favoring lower mortality with ECMO use. As expected, studies such as those of Wu MY et al. (21) and Meneveaus $\mathrm{N}$ et al. (28) that reported higher cardiac arrest rates in only the ECMO groups had ORs favoring lower mortality with non-ECMO treatment.

As noted previously, massive PE is associated with high inpatient and short-term mortality. ST reduces mortality; however, most of these patients do not receive them often due to contraindications. Major cardiovascular societies have recognized that there is a role for ECMO, particularly as a bridge to definitive therapies such as SE, CDT, or ST. As evident from our meta-analysis, the current literature is limited to case series and one registry with significant heterogeneity. To better understand which patients would benefit from ECMO, a large multicenter randomized control trial would be ideal; however, this would be difficult to conduct in a controlled manner, especially in patients with cardiac arrest where emergent therapies are needed. The development of sizeable multicenter quality improvement registries with all institutions following standardized protocol to utilize ECMO will help understand its role. The National Cardiogenic Shock Initiative (NSCI) is an ideal example of participating healthcare centers adopting the NSCI treatment algorithm and providing data from these patients (29, 30). Such initiatives help analyze the benefit of therapies such as ECMO and underscore the importance of best practices and define the standard of care. We can leverage existing programs such as the National PERT ${ }^{\text {TM }}$ Consortium to create initiatives similar to NCSI $(31,32)$.

Although ECMO can serve as a bridge to receiving advanced therapies, it should be noted that ECMO is not a benign procedure. Meta-analyses of ECMO in patients with cardiogenic shock or cardiac arrest have reported high rates of major bleeding (40.8\%), infection (30.4\%), acute kidney injury $(55.6 \%)$, and neurological complications (13.3\%) (33). Another systemic review reported a $13 \%$ rate of neurological complications which included intracranial hemorrhage $(5 \%)$ and ischemic stroke (5\%) (34). Pozzi M et al. reported prevalences of lower limb ischemia in $8 \%$ and stroke (hemorrhagic or ischemic) in $11 \%$ of patients.

\section{Limitations}

There were a number of limitations in our study. First, there was significant heterogeneity in our results, which is likely the 
result of differences in study cohorts and disease severity such as cardiac arrests among patients with massive PE. All of the studies were retrospective case series with varying levels of emphasis on ECMO as their clinical question. Second, studies were mostly single-center trials with small enrollment groups. There were no standard inclusion and exclusion criteria among the studies. As a result, they were subject to a significant risk of confounding or selection bias and limited generalizability. However, Egger's and Peter's test and the funnel plot showed no evidence of a small study effect.

Regarding decline effect and early-extreme bias, metaregression showed that publication year was not a significant covariate. Lastly, there was insufficient data to conduct subgroup analysis on key variables such as patients that experienced cardiac arrest or received advanced therapies such as ST, CDT, and SPE. These factors likely have a significant effect on patient outcomes and were not measured in this meta-analysis.

\section{Conclusion}

In recent years, ECMO is increasingly used in the management of acute massive PE. Although promising, there is a critical gap in the knowledge of the role and benefit of ECMO in treating acute massive PE. This meta-analysis provides a call to action to physicians and scientists caring for thousands of patients worldwide to strongly advocate for better data in evaluating ECMO's role in massive PE with particular attention paid to massive PE subgroups such as those with cardiac arrest and cardiogenic shock. The technology and protocol for ECMO use are already well-established, and the potential translation of future research is very high.

\begin{abstract}
Abbreviations AHA, America Heart Association; CI, Confidence interval; CDT, Catheter-directed therapies; ECMO, Venoarterial extracorporeal membrane oxygenation; ESC, European Society for Cardiology; NCSI, National Cardiogenic Shock Initiative; OR, Odds ratio; PE, Pulmonary embolism; PVR, Pulmonary vascular resistance; RV, Right ventricle; SPE, Surgical pulmonary embolectomy; ST, Systemic thrombolysis
\end{abstract}

\section{Declarations}

Ethics approval This article does not contain any studies with human participants or animals performed by any of the authors.

Conflict of Interest Dr. Sharma receives research grants from Vascular Medcure Inc, DalCor Pharma UK Ltd, and Portola. Dr. Giri is on the advisory board for Inari Medical and Astra Zeneca and has research grants from Boston Scientific. All other authors have no conflict of interest related to the work.

\section{References}

1. Centers for Disease C, Prevention. (2012). Venous thromboembolism in adult hospitalizations - United States, 2007-2009. MMWR. Morbidity and Mortality Weekly Report, 61(22), 401-404.

2. Rathbun, S. (2009). Cardiology patient pages. The Surgeon General's call to action to prevent deep vein thrombosis and pulmonary embolism. Circulation, 119(15), e480-e482.

3. Heit, J. A., Spencer, F. A., \& White, R. H. (2016). The epidemiology of venous thromboembolism. Journal of Thrombosis and Thrombolysis, 41(1), 3-14.

4. Sakr, Y., Giovini, M., Leone, M., Pizzilli, G., Kortgen, A., Bauer, M., et al. (2020). Pulmonary embolism in patients with coronavirus disease-2019 (COVID-19) pneumonia: A narrative review. Annals of Intensive Care, 10(1), 124.

5. Goldhaber SZ, Visani L, De Rosa M. Acute pulmonary embolism: Clinical outcomes in the International Cooperative Pulmonary Embolism Registry (ICOPER). Lancet. 1999;353(9162):13861389.

6. Marti, C., John, G., Konstantinides, S., Combescure, C., Sanchez, O., Lankeit, M., et al. (2015). Systemic thrombolytic therapy for acute pulmonary embolism: A systematic review and meta-analysis. European Heart Journal, 36(10), 605-614.

7. Stein, P. D., \& Matta, F. (2012). Thrombolytic therapy in unstable patients with acute pulmonary embolism: saves lives but underused. The American Journal of Medicine, 125(5), 465-470.

8. Weinberg, A., Tapson, V. F., \& Ramzy, D. (2017). Massive pulmonary embolism: Extracorporeal membrane oxygenation and surgical pulmonary embolectomy. Seminars in Respiratory and Critical Care Medicine, 38(1), 66-72.

9. Pasrija, C., Kronfli, A., George, P., Raithel, M., Boulos, F., Herr, D. L., et al. (2018). Utilization of veno-arterial extracorporeal membrane oxygenation for massive pulmonary embolism. The Annals of Thoracic Surgery, 105(2), 498-504.

10. Grant, C., Jr., Richards, J. B., Frakes, M., Cohen, J., \& Wilcox, S. R. (2021). ECMO and Right Ventricular Failure: Review of the Literature. Journal of Intensive Care Medicine, 36(3), 352-360. https://doi.org/10.1177/0885066619900503.

11. Yusuff, H. O., Zochios, V., \& Vuylsteke, A. (2015). Extracorporeal membrane oxygenation in acute massive pulmonary embolism: A systematic review. Perfusion, 30(8), 611-616.

12. Stroup, D. F., Berlin, J. A., Morton, S. C., Olkin, I., Williamson, G. D., Rennie, D., et al. (2000). Meta-analysis of observational studies in epidemiology: A proposal for reporting. Meta-analysis Of Observational Studies in Epidemiology (MOOSE) group. Jama, 283(15), 2008-2012.

13. Moher, D., Liberati, A., Tetzlaff, J., Altman, D. G., \& Group P. (2009). Preferred reporting items for systematic reviews and metaanalyses: The PRISMA statement. PLoS Medicine, 6(7), e1000097.

14. Rao, G., Lopez-Jimenez, F., Boyd, J., D'Amico, F., Durant, N. H., Hlatky, M. A., et al. (2017). Methodological standards for metaanalyses and qualitative systematic reviews of cardiac prevention and treatment studies: A scientific statement from the American Heart Association. Circulation, 136(10), e172-ee94.

15. Giri, J., Sista, A. K., Weinberg, I., Kearon, C., Kumbhani, D. J., Desai, N. D., et al. (2019). Interventional therapies for acute pulmonary embolism: Current status and principles for the development of novel evidence: a scientific statement from the American Heart Association. Circulation, 140(20), e774-e801.

16. Cumpston, M., Li, T., Page, M. J., Chandler, J., Welch, V. A., Higgins, J. P., et al. (2019). Updated guidance for trusted systematic reviews: A new edition of the Cochrane Handbook for Systematic Reviews of Interventions. Cochrane Database of Systematic Reviews, 10, ED000142. 
17. Peters, J. L., Sutton, A. J., Jones, D. R., Abrams, K. R., \& Rushton, L. (2006). Comparison of two methods to detect publication bias in meta-analysis. Jama, 295(6), 676-680.

18. Egger, M., Davey Smith, G., Schneider, M., \& Minder, C. (1997). Bias in meta-analysis detected by a simple, graphical test. Bmj, 315(7109), 629-634.

19. Mandigers, L., Scholten, E., Rietdijk, W. J. R., den Uil, C. A., van Thiel, R. J., Rigter, S., et al. (2019). Survival and neurological outcome with extracorporeal cardiopulmonary resuscitation for refractory cardiac arrest caused by massive pulmonary embolism: A two center observational study. Resuscitation, 136, 8-13.

20. Maggio, P., Hemmila, M., Haft, J., \& Bartlett, R. (2007). Extracorporeal life support for massive pulmonary embolism. The Journal of Trauma, 62(3), 570-576.

21. Wu, M. Y., Liu, Y. C., Tseng, Y. H., Chang, Y. S., Lin, P. J., \& Wu, T. I. (2013). Pulmonary embolectomy in high-risk acute pulmonary embolism: The effectiveness of a comprehensive therapeutic algorithm including extracorporeal life support. Resuscitation, 84(10), 1365-1370.

22. Gibbon Jr., J. H., \& Hill, J. D. (1982). Part I. The development of the first successful heart-lung machine. The Annals of Thoracic Surgery, 34(3), 337-341.

23. Noah, M. A., Peek, G. J., Finney, S. J., Griffiths, M. J., Harrison, D. A., Grieve, R., et al. (2011). Referral to an extracorporeal membrane oxygenation center and mortality among patients with severe 2009 influenza A(H1N1). Jama, 306(15), 1659-1668.

24. Elbadawi, A., Mentias, A., Elgendy, I. Y., Mohamed, A. H., Syed, M. H., Ogunbayo, G. O., et al. National trends and outcomes for extra-corporeal membrane oxygenation use in high-risk pulmonary embolism. Vascular Medicine (London, England), 2019, 24(3), 230-233.

25. Konstantinides, S. V., \& Meyer, G. (2019). The 2019 ESC Guidelines on the Diagnosis and Management of Acute Pulmonary Embolism. European Heart Journal, 40(42), 34533455. https://doi.org/10.1093/eurheartj/ehz726.

26. Pozzi, M., Metge, A., Martelin, A., Giroudon, C., Lanier Demma, J., Koffel, C., et al. (2020). Efficacy and safety of extracorporeal membrane oxygenation for high-risk pulmonary embolism: A systematic review and meta-analysis. Vascular Medicine, 25(5), 460467.
27. Moon, D., Lee, S. N., Yoo, K. D., \& Jo, M. S. (2018). Extracorporeal membrane oxygenation improved survival in patients with massive pulmonary embolism. Annals of Saudi Medicine, 38(3), 174-180.

28. Meneveau, N., Guillon, B., Planquette, B., Piton, G., Kimmoun, A., Gaide-Chevronnay, L., et al. (2018). Outcomes after extracorporeal membrane oxygenation for the treatment of high-risk pulmonary embolism: A multicentre series of 52 cases. European Heart Journal, 39(47), 4196-4204.

29. Basir, M. B., Kapur, N. K., Patel, K., Salam, M. A., Schreiber, T., Kaki, A., et al. (2019). Improved outcomes associated with the use of shock protocols: Updates from the National Cardiogenic Shock Initiative. Catheterization and Cardiovascular Interventions, 93(7), 1173-1183.

30. Samsky, M. D., Krucoff, M. W., Morrow, D. A., Abraham, W. T., Aguel, F., Althouse, A. D., et al. (2020). Cardiac safety research consortium "shock II" think tank report: Advancing practical approaches to generating evidence for the treatment of cardiogenic shock. American Heart Journal, 230, 93-97.

31. Schultz, J., Giordano, N., Zheng, H., Parry, B. A., Barnes, G. D., Heresi, G. A., et al. (2019). EXPRESS: A Multidisciplinary Pulmonary Embolism Response Team (PERT) - Experience from a national multicenter consortium. Pulmonary Circulation, 9(3), 2045894018824563. https://doi.org/10.1177/2045894018824563.

32. Myc, L. A., Solanki, J. N., Barros, A. J., Nuradin, N., Nevulis, M. G., Earasi, K., et al. (2020). Adoption of a dedicated multidisciplinary team is associated with improved survival in acute pulmonary embolism. Respiratory Research, 21(1), 159.

33. Cheng, R., Hachamovitch, R., Kittleson, M., Patel, J., Arabia, F., Moriguchi, J., et al. (2014). Complications of extracorporeal membrane oxygenation for treatment of cardiogenic shock and cardiac arrest: a meta-analysis of 1,866 adult patients. The Annals of Thoracic Surgery, 97(2), 610-616.

34. Sutter, R., Tisljar, K., \& Marsch, S. (2018). Acute neurologic complications during extracorporeal membrane oxygenation: A systematic review. Critical Care Medicine, 46(9), 1506-1513.

Publisher's Note Springer Nature remains neutral with regard to jurisdictional claims in published maps and institutional affiliations. 